\title{
The analysis of efficiency of GFRP and CFRP covers to reinforce concrete beams under various conditions
}

\author{
Seyede Fateme Khamesi* \\ Department of Architecture, Islamic Azad University, Bushehr Branch, Bushehr, Iran
}

\section{A R T I C L E I N F O}

\section{Article history:}

Received 10 June 2016

Received in revised form

29 July 2016

Accepted 30 July 2016

\section{Keywords:}

GFDRP

CFRP

FRP

Bending strength- Shear strength

Solid and hollow column

\begin{abstract}
A B S T R A C T
Application of Fibre Reinforced Plastic (FRP) composites has been very widely developed for seismic reclamation during recent years. One of the important reasons that may be implied for selection of these materials is the high tensile strength, low-weight, and also flexibility of the system in these materials and very high durability of them. Rather than describing of installation technique of recent studies, it has been dealt with bending- shear behavior in the reinforced concrete beams with Glass- Fibre Reinforced Plastic (GFRP) and Carbon Fibre Reinforced Plastic (CFRP) composites. For this purpose, the concrete reinforced beams have been analyzed by various techniques and using built-in glass and carbon fibers. The carbon- fiber built samples without the end brace and other samples with end- brace were anchored by glass fibers. Similarly, glass-fiber reinforced plastic (GFRP) beams were built with and without bracing at end and reserved under laboratory conditions. These fibers have been installed in tensile point of beams and by means of epoxy adhesive and also one sample was built as control beam without using fibre. On the other hand, some solid and hollow beams were prepared as well. The results of experiments indicate that rates of rising strength for non- bracing carbon and glass were about $19-40 \%$ and $8-43 \%$ respectively and the strength were increased for braced carbon and glass $17-75 \%$ and $10-82 \%$ respectively. In hollow cylindrical column enclosed the compressional strength has increased $66 \%$ in one CFRP layer, $96 \%$ in two CFRP layers, and $123 \%$ in three CFRP layers while application of GFRP has increased compressional strength up to $36 \%$ in one GFRP layer, $63 \%$ in two GFRP layers, and $105 \%$ in three GFRP layers for hollow cylindrical column. In solid cylindrical enclosed by one CFRP layer the compressional strength has increased $71 \%, 138 \%$ in two CFRP layers, and $154 \%$ in three CFRP layers while application of one GFRP layer has increased compressional strength $45 \%$ and in two layer GFRP layer $79 \%$ and in three GFRP layers it has been increased up to $144 \%$ for solid cylindrical column. The rate of increase in final resistance at beams reinforced by bending- shear strength is greater than final resistance in other beams.
\end{abstract}

(C) 2016 The Authors. Published by IASE. This is an open access article under the CC BY-NC-ND license (http://creativecommons.org/licenses/by-nc-nd/4.0/).

\section{Introduction}

With respect to massive concentration of buildings together, the measures relating to reconstruction and repair of the existing structures have been noticed as an alternative for demolition and construction of new structures all the time. Whereas period of 80 to 100 years are usually predicted as useful life for reinforced concrete

\footnotetext{
* Corresponding Author.

Email Address: mercedekhamesi@gmail.com

http://dx.doi.org/10.21833/ijaas.2016.07.015

2313-626X/C) 2016 The Authors. Published by IASE.

This is an open access article under the CC BY-NC-ND license

(http://creativecommons.org/licenses/by-nc-nd/4.0/)
}

structures thus the given structure should be capable to respond to various requirements during this period but the problem here is that all of needs may not be predictable at time of design and construction of structures. Despite of growing tendency to use FRP sheets for strength and rising useful life in these structures, one of the cases about which there is not yet general perception is the surface adhesion and continuity among repairing systems and resisting by bedding concrete.

The weak adhesion of FRP to concrete and low surface resistance in concrete reduces remarkably the resistance cause by implementation of FRP and leads to premature and unexpected fractures as a result the safety and efficiency of attached FRPs to 
external part of concrete segments have been challenged by the relevant practitioners.

Following to attachment of reinforced sheet to external surface of concrete at one end, there is no continuity around this area by concrete (Arduini and Nanni, 1997) and due to damaging, weathering, and environmental factors and exploitation the surface resistance has been usually reduced in concrete that is determinant in consolidation of the joint (Naderi, 2008).

It is necessary to have knowledge about real resistance (strength) of concrete in situ to ensure from quality of the conducted new works, effect of ambient factors, and exploitation on the existing concrete structure and purposes of recovery and resisting in structures.

Therefore, conditions and resistance of bedding concrete should be analyzed and calculated in order to determine capacity of resisting by FRP.

One of the latest innovated techniques for determination of surface resistance is twist-off method (Naderi, 2007) out of the given advantages one can refer to simplicity, high precision, low variance coefficient, accelerated execution, low-cost, partial damage, and high iteration potential. Similarly, execution of this technique does not require prior skill and planning and constraint of sample dimensions does not create problem in doing test (Naderi, 2007).

Although many studies indicate that rising concrete strength is followed by increase in final adhesion resistance, the exponential concrete strength- dependent equations show some differences in this field. Whereas References (Chajes et al., 1996; Horiguchi and Saeki, 1997; Nakaba et al., 2001) have presented linear relations proportional to $\mathrm{f}_{C}^{\prime 0.19}, \mathrm{f}_{C}^{\prime 1 / 5}, \mathrm{f}_{C}^{\prime 2 / 3}, \mathrm{f}_{C}^{\prime 1 / 2}$, the posited assumptions in these sources were only based on few numbers of laboratory data that may not propose the result of adhesion resistance and dependency on concrete strength. On the other hand, the conducted tests by Sena- Cruz et al. have suggested low effect of concrete strength on adhesion resistance.

Therefore, the subject of concrete strength effect on adhesion resistance of FRP sheets on concrete seems as necessary so for this reason the twist-off method has been utilized to determine strength of in-situ concrete in the present studies. One of the other effective factors on adhesion resistance of FRP sheets to concrete is preparation of surfaces.

Even sometimes before application of FRP, some investigations have been carried out about effect of surface coarseness on concrete adhesion strength to concrete (Wambold and Henry, 1982; Abu-Tair et al., 2000; Talbot et al., 1994; Julio et al., 2004; Santos and Julio, 2007). There are some studies (Toutanji and Ortiz, 2001; Mitsui et al., 2000; Matana et al., 2005; Myers et al., 2007; Li and Ghebreyesus, 2006; Seo et al., 2012; Yuan et al., 2012; Chen and El-Hacha, 2013) regarding effect of surface preparation in application of FRP where the results of these studies signify that preparation of surfaces by means of water pressure and sandblasting techniques are best methods for creating efficient adhesion For FRP on bedding concrete. It should be noticed that the features of the used adhesive also impact on adhesion resistance of FRP sheets on concrete. According to the existing reports, as the consuming adhesive is softer, the adhesion resistance will be greater (Dai et al., 2005; 2002).

Moreover, some studies have been conducted by references (Gao et al., 2004; Yoshizawa et al., 2000) regarding relationship among composition and type of adhesives. Likewise, it has been shown in recent numerical studies done by Benyoucef et al. (2007) that increase in thickness of adhesive layer might lead to noticeable reduction on tolerable surface stresses. Similarly with respect to investigations of Nanni and Arduini (Thomas et al., 2012), the vertical stresses are directly exerted on connection joint proportional to adhesive thickness. Thus the thinner adhesive layers reduce probability for breakdown and disjoint of concrete- adhesive connection.

These researchers have explored effect of various parameters on rising final strength in bending resistance of beams with simple support and the given results suggested that following to reduced FRP hardness, the separation effect may practically play lower role for concrete fixed strength.

With respect to goals of study, it should be noticed that the concrete bedding strength is deemed as very important in bending and shear strength, interlaminar adhesion of FRP, and concrete since the bedding concrete should be adequately resistant to tolerate direct tensile and shear stresses and capable to transfer them to FRP.

FRP detachment in reinforced concrete beams usually occurred at point of high stress concentration near to the end points and the disjoint positions of FRP and places of fractures present at lower concrete layer where the internal force in FRP sheet is not capable to be transferred between two materials to the lower layers by shear stresses (Buyukozturk et al., 2004).

The path of detachment spreading depends on specifications of bedding concrete, FRP, and joint surface (adhesive) and typically this path tends to the least resistance that is usually seen in concrete with respect to analysis in the conducted studies (Buyukozturk et al., 2004). As usual, detachment of FRP occurs at concrete surface under lower loads and in brittle form that is followed by noticeable breakdown. It should be noticed that due to impact of compression rate within cast on surface of a concrete piece work, contact to casting oils, inadequate hydration of cement, and also effect of damaging factors have stark difference from internal resistance in concrete piece work (Naderi, 2011; 2009).

The hybrid composition of fibers may be followed by potential benefits for improvement of concrete features such as reduction of total cost for production of concrete (Correia et al., 2009; Neagoe and Gil, 2014; Mendes et al., 2011; Mutsuyoshi et al., 2010; Gonilha et al., 2014; Dalalbashi et al., 2012). 
When the fibers are divided into smaller parts this leads us to have more compressed and uniform distribution throughout the concrete and this reduces contractive fractures and improvement in strength of concrete after occurrence of fracture. This point is very important for us to have a composition of fibers with higher and lower modulus in order to prevent from occurrence of smaller and bigger fractures. Similarly, various lengths of fibers may be efficient in control of fracture. Some of studies indicate the general advantages of composite fibers.

In spite of describing installation technique like recent studies, the bending- shear behavior of reinforced concrete beams as a critical concern has been analyzed in various layers with GFRP and CFRP fibers.

\section{Methodology}

\subsection{Carbon fibers}

Carbon is an element with density $2.25 \mathrm{~g} . \mathrm{cm}^{3}$ and includes various crystalline forms. The carbon fibers are very thinner than human's hair and despite of great volume of application they are relatively expensive and due to appropriate strength they are fragile against cyclic loadings with stress ratio of $0.54 f_{f u}$ and high resistance against corrosion and rate of ductility is low at time of failure.

\subsection{Glass fibers}

The glass fibers are assumed as the most prevalent and frequently used fibers in composite industry and the glass fibers are classified according to type of composition of used materials in their preparation in which their advantages and disadvantages include low cost, high tensile strength, high chemical resistance, low modulus of elasticity, relatively high specific weight, sensitivity to grinding during transport, low fatigue resistance by toleration of stress ratio of $0.2 \mathrm{f}_{\mathrm{fu}}$, and fragility respectively as features of these fibers.

\subsection{The construction phases of samples}

The beams were built by means of concrete mixture with water-to-cement ratio 50 and the coarse - grained stony materials and gravel with maximum diameter of $16 \mathrm{~mm}$ and sand with softness modulus 209 based on ASTM standard and after 24 hours the given cast opened and they were stored in water tank for 28 days.

\subsection{Surface preparation}

It comprised of all operations that prepared element surface for connection of FRP composite and due to importance of connection of FRP layer, this phase was carried out with great care including removal of additional soft materials from the surface of work piece surface and cleaning of materials such as cement grout residue on surface of the sample and removal of chemicals as well as polishing the surface by grindstone so that the unevenness to be reduced up to less than one millimeter and finally FRP was installed on surface of beam by epoxy adhesive under laboratory conditions (in vitro) at about temperature $20^{\circ} \mathrm{C}$.

\subsection{General specifications of beams}

With respect to the existing facilities and constraints of equipment in the lab, size of samples was considered by length $1.2 \mathrm{~m}$ and cross section of $14.8 \times 10 \mathrm{~m}$ in which two bars (Ø10) were used to strengthen tensile area and $1 \varnothing 8$ for reinforcement of compressional part of beam and reinforcement $\emptyset 6$ with $6 \mathrm{~cm}$ distance as stirrup and loading was exerted up to phase of beam destruction at uniform velocity. So the results of test were recorded as displacement loading curve in which some gauges with precision rate (0.001in) were used for measurement of strain displacement at the middle of beam and place of force exertion. FRP fibers (length: $90 \mathrm{~cm}$ and width: $10 \mathrm{~cm}$ ) were installed with $5 \mathrm{~cm}$ distant from the support in such a way that the samples were stored before loading under ambient lab conditions for one week. The concrete used in this study included compressional strength $25 \mathrm{mPa}$ and the used steel with failure strength $400 \mathrm{mPa}$. The modulus of elasticity $240 \mathrm{KN} / \mathrm{mm}^{2}$ is designated for carbon and $70 \mathrm{~mm}$ diameter of glass for carbon 175 and for glass with diameter 17, the final strain is designated as 1.5 for carbon and for glass 3.3, the tensile strength is $3650 \mathrm{~N} / \mathrm{mm}^{2}$ for carbon and it is 2280 for glass and specific weight is $290 \mathrm{~g} / \mathrm{m}^{2}$ for carbon and 425 for glass. All of the built beams were designed according to above procedure with observing the minimum and maximum reinforcements in beam and based on soft failure.

\subsection{Method of preparation of beams}

We consider non-reinforced sample under title of Ref. as reference beam in the case study where no repair was executed in this sample and the given sample has been reinforced only by means of steel inside the beam. In order to analyze CFRP, we utilize three beams with 1 to 3 carbon layers with diameter $0.0165 \mathrm{~mm}$ and for GFRP with three beams and 1 to 3 glass fiber layers with diameter of $0.0165 \mathrm{~mm}$ respectively as well. Moreover, regarding the beam with no bracing end the other group of beams has been braced in $\mathrm{u}$-form for final bracing by glass fibers (size: $15 \times 25 \mathrm{~cm}$ ) that are shown by symbol (end).

\subsection{Hollow and solid concrete}

The concrete mixture was designed by means of Abadeh cement type-II, washed sand, pea gravel, and based on water-to-cement ratio 0.60 to achieve 
characteristic resistance 20MPa. The small scale cylindrical columns were built with height $30 \mathrm{~cm}$ and diameter $15 \mathrm{~cm}$. All of samples were processed in vapor bath for 28 days. After drying of samples the upper layer of samples was removed using minifrieze device and the current corroded points on them was filled by express epoxy (primer) and all of samples were smoothened. In any 7- member group, one sample was designated as control element and three samples were bounded with CFRP and three other samples with GFRP as one-layer, two- layer, and three-layer binding.
To analyze bending behavior of beam, two straingauges were employed at middle points of beam and location force exertion in each of these points some strain-gauges (precision: 0.001in) were utilized at the middle of beam and place of force exertion to measure displacement and a beam was tested under loading to measure behavior of beam without recovery and behavior of other beams was measured in comparison to reference beam. In Table 1, bending strength of the resisted samples are given in respective of reference beam in which beams with end bracing are indicated by symbol 'end'.

\section{Results}

Table 1: Bending strength

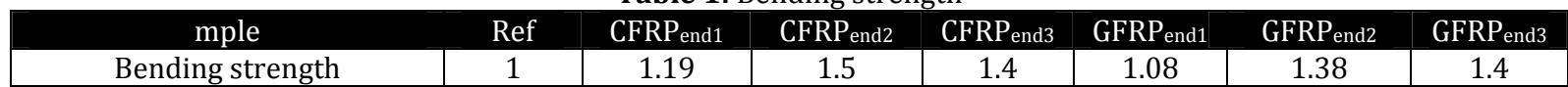
3.

The laboratory results are shown in Fig. 1 to Fig.

The comparison between computational results mentioned in this procedure has been analyzed by experimental results and the given results display difference in some of samples especially the glassfiber reinforced plastic samples. So this difference may be due to this fact that the procedure does not utilize glass fiber for bending reinforcement and it calculates bending strength by considering carbon fibers while the detachment conditions have been designated in these fibers.



Fig. 1: Increase in bending strength at samples

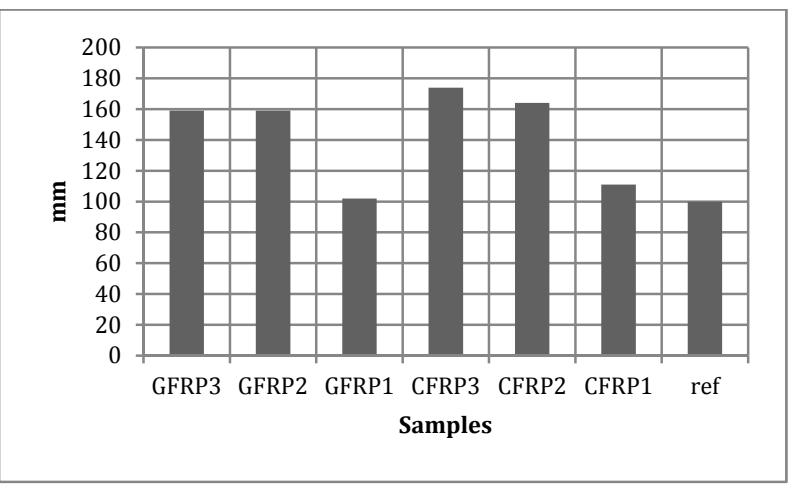

Fig. 2: Final rise in samples

And as it observed in Fig. 1 to Fig. 3, the maximum increase in loading occurred in sample with three layers of glass fiber and force quantity $(83 \mathrm{KN} / \mathrm{m})$ that is $72 \%$ of increase compared to reference beam. Similarly, the rate of final rise in this sample is $7.495 \mathrm{~mm}$ and the minimum rate of increase of loading was observed $49.5 \mathrm{KN} / \mathrm{m}$ in onelayer glass fiber sample. Likewise, the maximum ductility was seen in three-layer glass as $11.684 \mathrm{~mm}$ and the minimum rate of ductility was observed in three-layer carbon with $4.14 \mathrm{~mm}$.

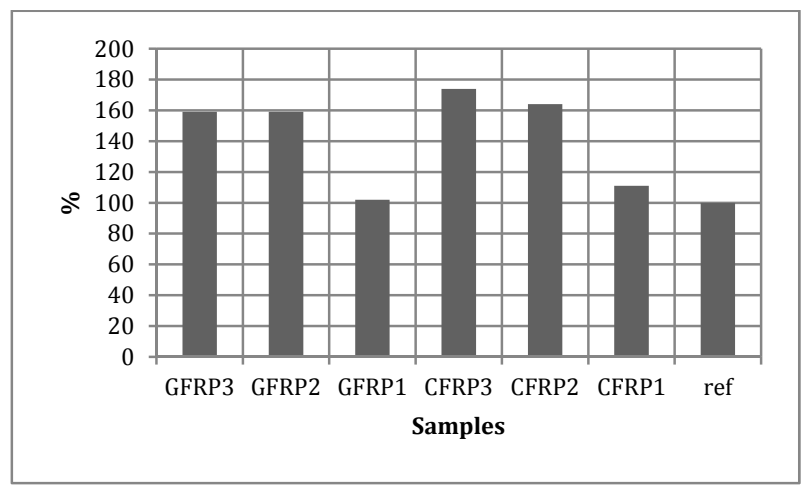

Fig. 3: Percentage of increase in bending strength in samples compared to reference beam

Using FRP sheets with carbon layers increased bending capacity of beams and this bending strength is added as FRP layer is increased. So the quantity of this increase is $15.5 \%$ for one layer, $46.6 \%$ for two layers, and $38.86 \%$ for three layers. As it seen, increase in diameter of layers may relatively contribute to increase bending strength in samples and after a certain level, diameter of layers has no effect in increased bending strength of samples and this quantity of bending potential relatively depends on rising layer where there is an optimal amount for increase in layers. Of course, this increased in bending capacity will be followed by reducing amount of ductility in beams.

No failure occurred in FRP system in any case of beams and all cases of detachment of FRP were accompanied to concrete coverage at the end of FRP was the main reason for failure in sample. And this indicates that capacity of fibers was not entirely used. At the same time it similarly displays high tensile capacity in this system. If this system is properly used it may be used as good recovered materials in structures and also under reinforcement 
mode failure of beam is of brittle type. No trace of warning fracture is seen in the system. Therefore it should be behaved necessarily with caution upon using this system and employ this system with accurate recognition. Likewise, the shear failure of beam under increase in number of beams should be addressed when using this system (Fig. 4).

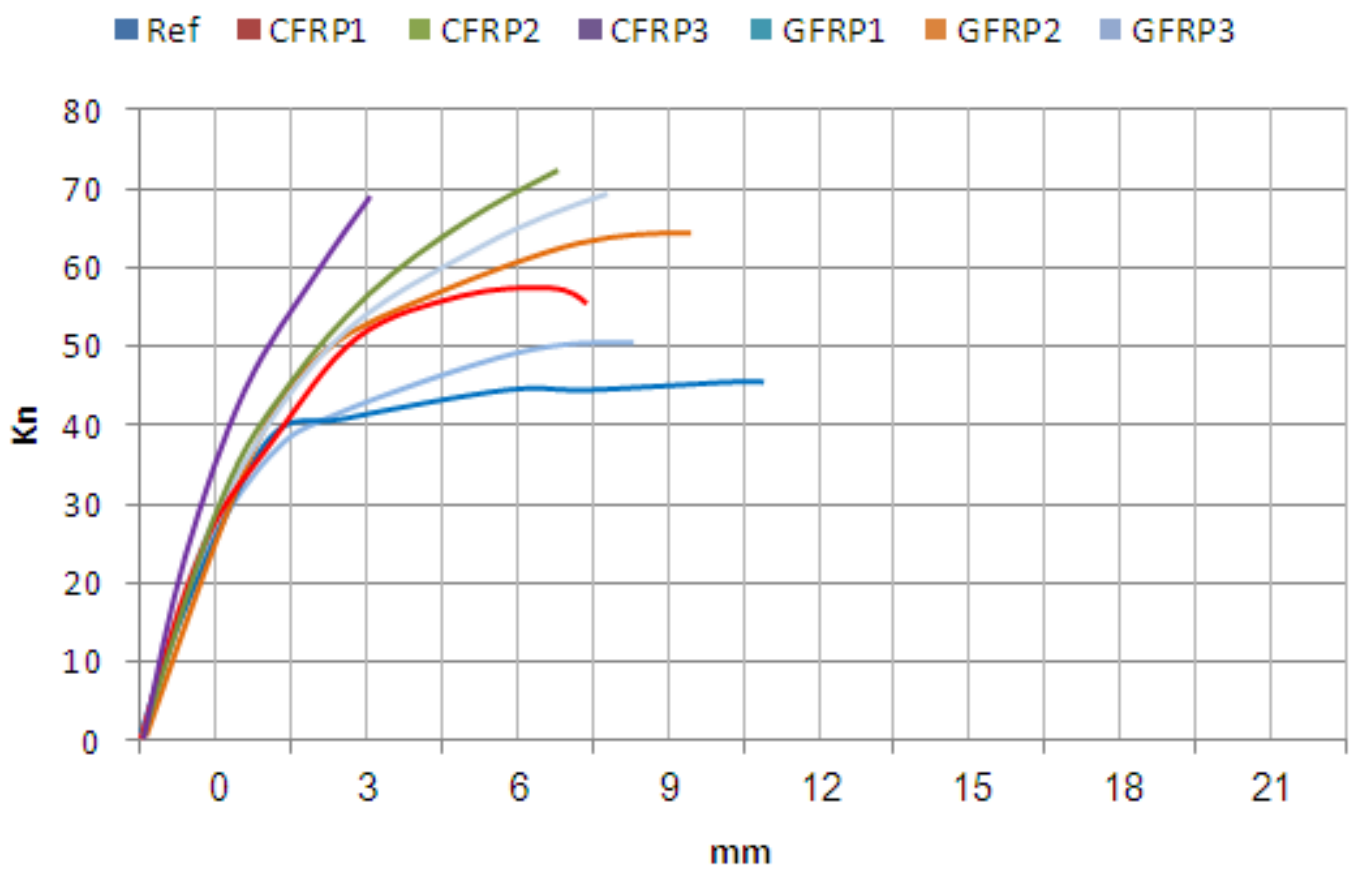

Fig. 4: Force and displacement

And as it observed in Fig. 4, increase in diameter of layers caused rising hardness in samples. Failure occurred in four samples because of flakiness (cleavage) of layers at the end of fibers where this is due to concentration of stress at the end of fibers.

Simultaneously presence of FRP sheets in tensile area of beam and U-shape binding of FRP sheet at the end of sheets in tensile area at bracing samples with carbon fibers had positive effect on bending behavior and ductility in beams. The presence of FRP bindings prevented from increase in depth of fractures in the area where shear stress was normal and at maximum level (Table 2) where this causes the phenomenon of flakiness not to be visible at the end of fibers such as in samples without end-bracing. Therefore, loading is extremely increased in beams and under such condition it can be almost said the potential of flakiness in FRP is used optimally (Fig. 5 to Fig. 8).

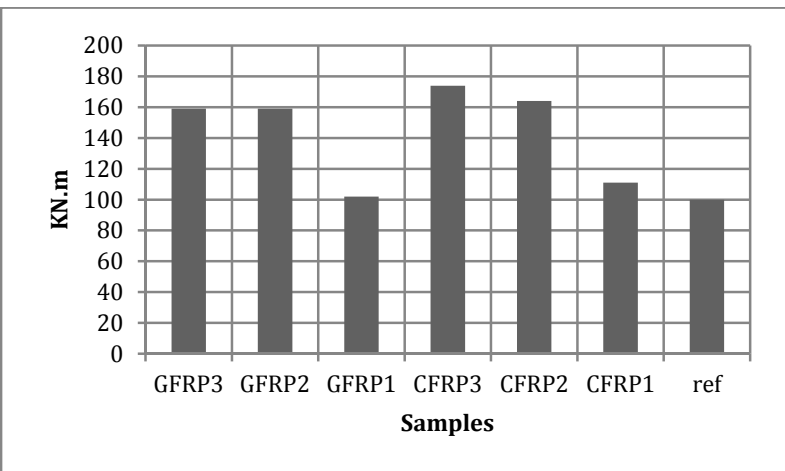

Fig. 5: Increase in bending strength at the braced samples
According to former samples in bracing samples with glass fibers, the end of FRP was braced by glass fibers as well but it was different in that the glass fibers have been utilized instead of carbon fibers for bending reinforcement of beams and whereas the glass fibers possess high potential for strain compared to carbon fibers as a result ductility of the reinforced samples was greater than in carbon fibers and in many cases the final ductility of the samples reinforced with glass fibers was higher than in control beam (Fig. 5 to Fig. 8). Since the end of fibers was braced as a result loading was noticeably increased in samples; of course, the maximum displacement was seen in sample with three layer among all of samples and displacement in this sample was even observed greater than in reference beam.

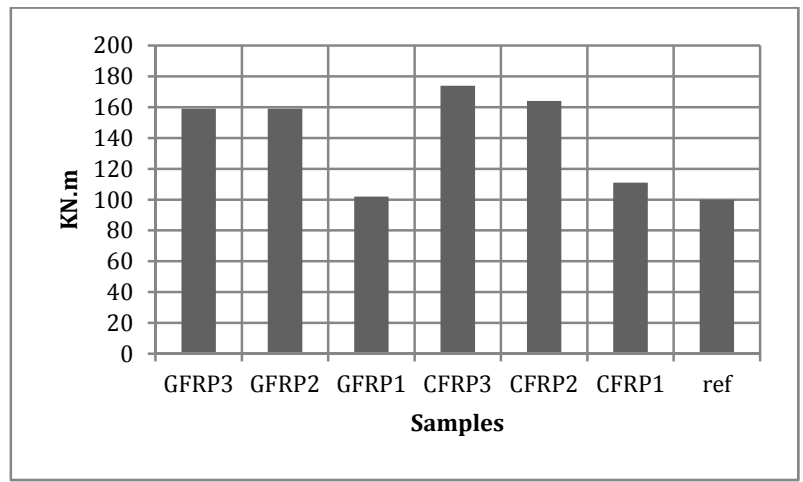

Fig. 6: Final rise in the braced samples 


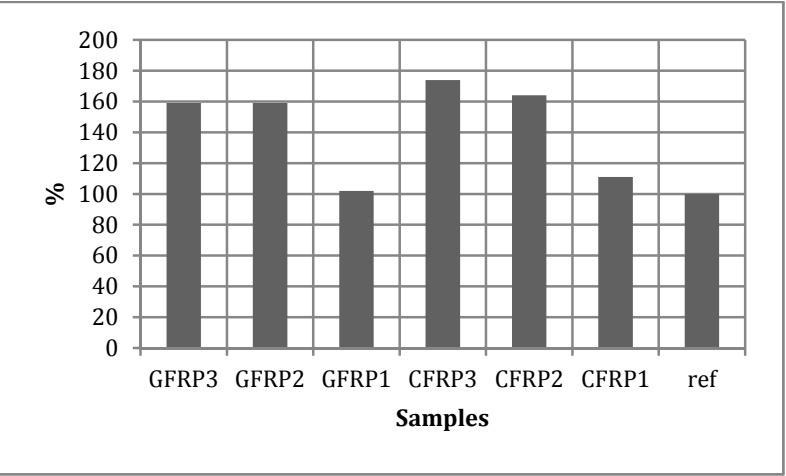

Fig. 7: Percentage of increase in bending strength at the braced samples compared to reference beam
Therefore, we observed FRP failure in those samples that were reinforced by one layer of glass fiber. But detachment of glass fiber were accompanied to concrete coverage was the main reason for failure in samples especially in two other samples. The force was tolerated in tensile part of beam only by fibers at the final phases of loading on beam while concrete only played filling role in beam and it was practically out of order so that finally the failure in U-shape brace was the reason for breakdown of beams (Fig. 9 to Fig. 12).

Ref $\square$ CFRP1 $\square$ CFRP2 $\square$ CFRP3 $\square$ GFRP1 $\square$ GFRP2 $\square$ GFRP3

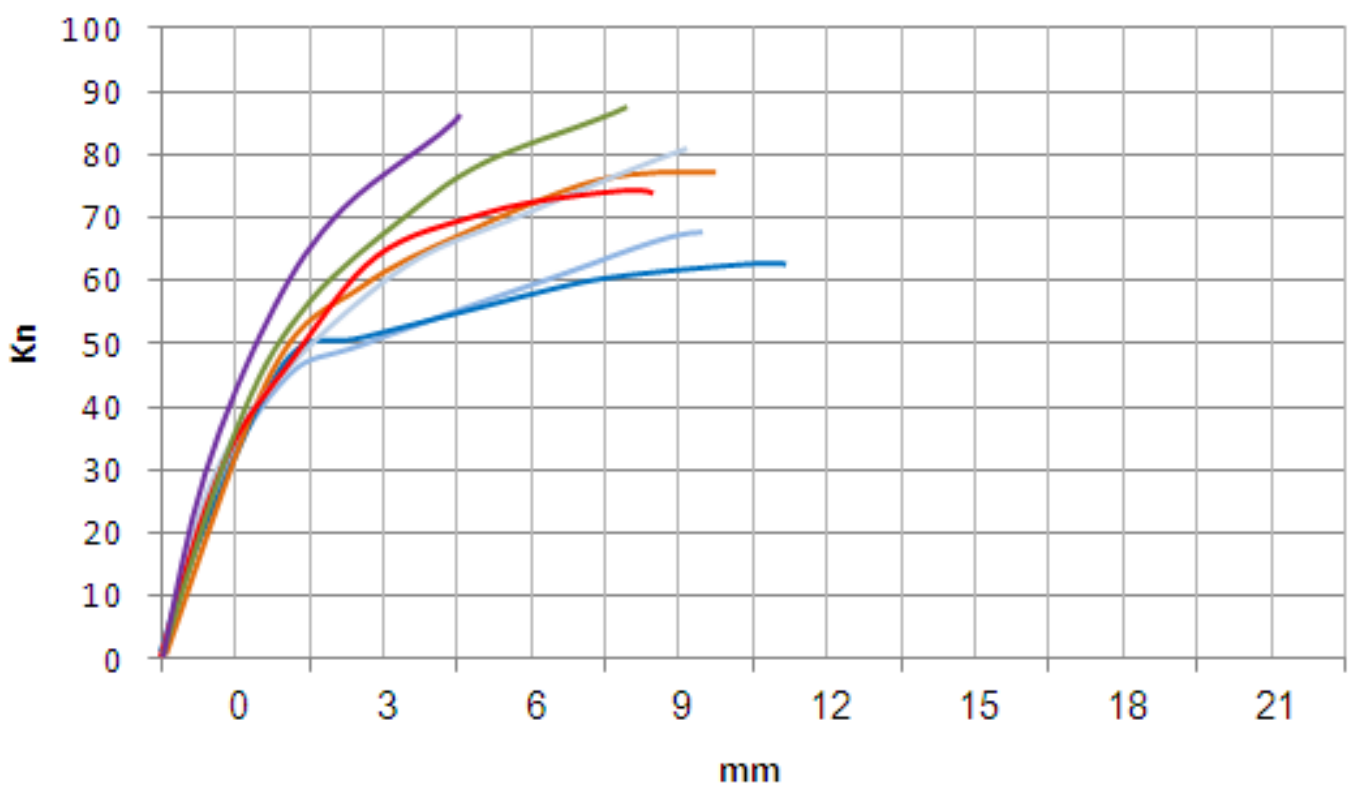

Fig. 8: Force and displacement of the braced samples

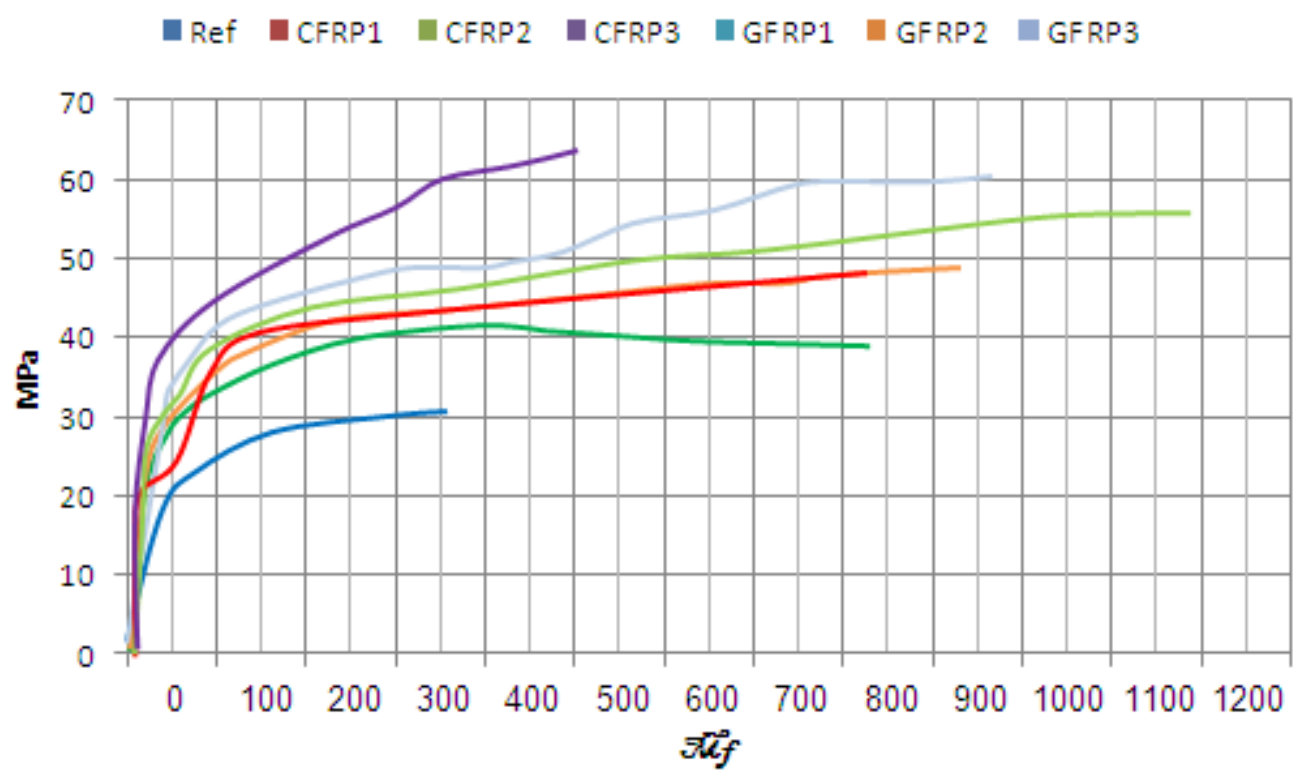

Fig. 9: Transversal stress- strain in hollow cylindrical column 


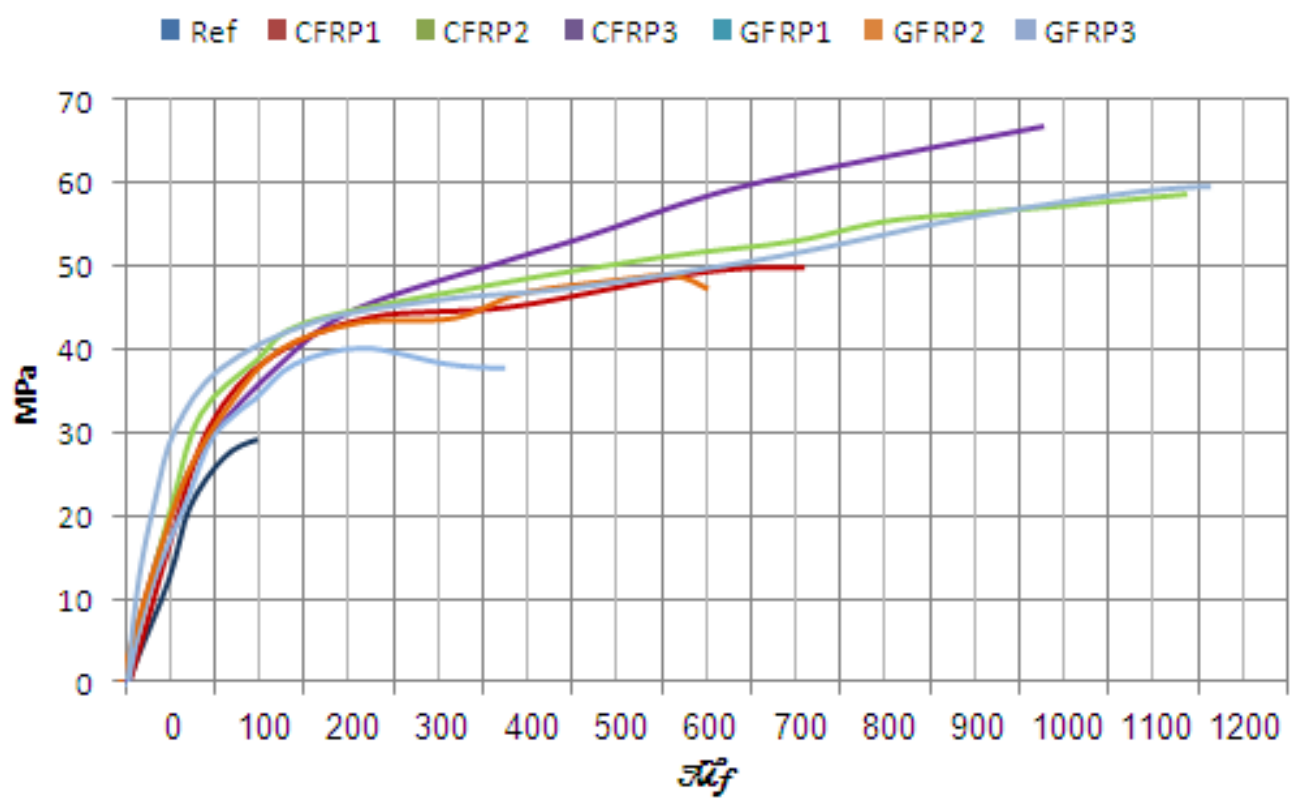

Fig. 10: Diagram of axial stress- strain in hollow cylindrical column

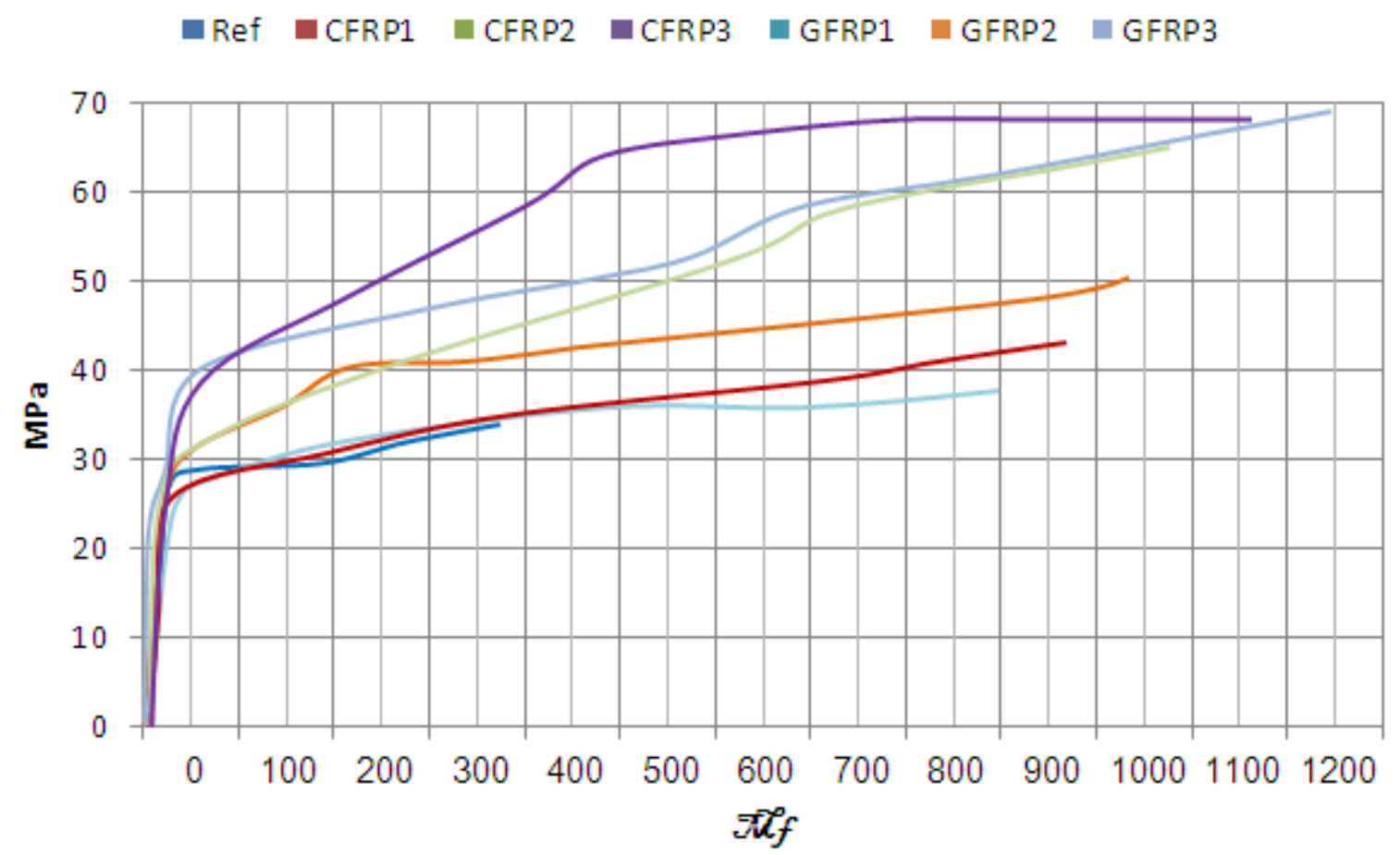

Fig. 11: Diagram of transversal stress- strain in solid cylindrical column

Table 2: Loading in the braced beams

\begin{tabular}{|c|c|c|c|c|c|c|c|}
\hline Sample & Ref & $\mathrm{CFRP}_{\text {end1 }}$ & $\mathrm{CFRP}_{\text {end2 }}$ & $\mathrm{CFRP}_{\text {end } 3}$ & GFRP $_{\text {end1 }}$ & $\mathrm{GFRP}_{\text {end2 }}$ & $\mathrm{GFRP}_{\text {end3 }}$ \\
\hline Bending strength & 1 & 1.17 & 1.71 & 1.75 & 1.1 & 1.61 & 1.82 \\
\hline
\end{tabular}

As it visible in Fig. 9 to Fig. 12, application of in binding of columns has increased their strength and ductility in all of samples. Compared to GFRPbinding column, CRFP- binding columns possessed higher compressional strength, ductility, axial and transversal hardness. In hollow cylindrical column enclosed with one CRFP layer compressional strength has been increased $66 \%$ and this resistance was increased $96 \%$ in two-CRFP layers and $123 \%$ in three- CRFP layers while application of one-GFRP layer caused increase $36 \%$ in compressional strength and $63 \%$ in two GFRP layers and $105 \%$ in three- GFRP layers within hollow cylindrical column. The compressional strength has been increased 71\% in solid cylindrical column with one CFRP-layer, and $138 \%$ with two- CFRP layers, and $154 \%$ with threeCFRP layers while application of one- GFRP layer has increased $45 \%$ in compressional strength of solid cylindrical column and 79\% with two- GFRP layers and $144 \%$ with three- GFRP layers. 
Ref $\square$ CFRP1 $\square$ CFRP2 $\quad$ CFRP3 $\square$ GFRP1 $\quad$ GFRP2 $\quad$ GFRP3

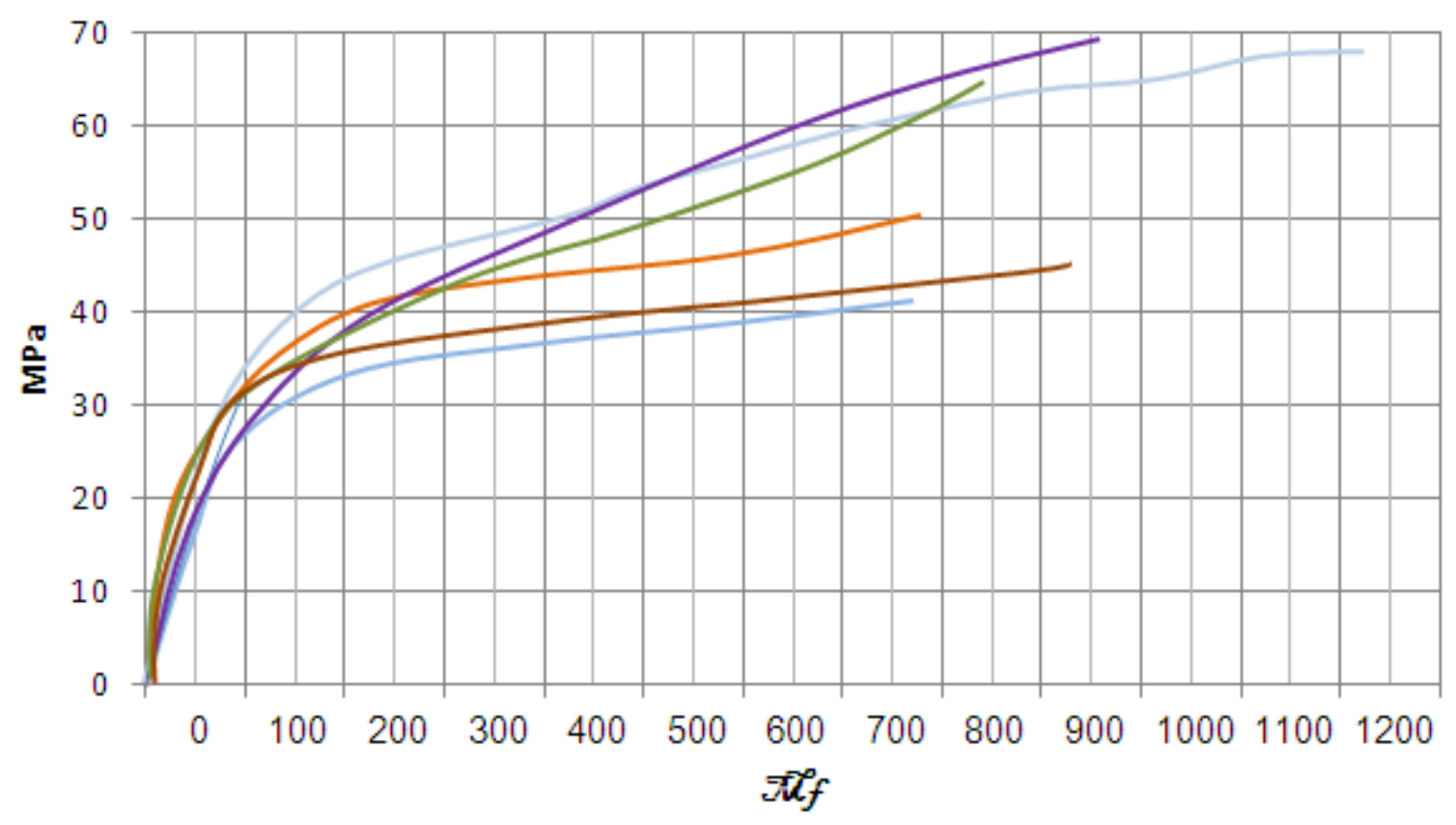

Fig. 12: Diagram of axial stress- strain in solid cylindrical column

With respect to these results and a general comparison one may consider the rate of fiberbinding on hollow samples less than in solid ones although binding in hollow samples was very noticeable and at the same time the rate of effect by CFRP fibers is greater than by GFRP. We come to the following results by observation of the given results from the experiments to analyze bending- shear strength under almost identical conditions for these beams. The final resistance and hardness of the reinforced beams are increased in comparison to reference beam while ductility was reduced in them.

The failure is of shear type in all of the reinforced beams. Among the reinforced beams, the carbonreinforced beams have higher final resistance than other beams but their ductility is lower than the other beams. Compared to final strength of other beams, the rate of increase in final strength is greater in beams that have been reinforced by bendingshear force. The subscript 1 denotes bending reinforcement in samples and subscript-2 expresses bending- shear reinforcement (Fig. 13).

\section{Conclusion}

Rather than describing of installation technique of recent studies, the study has been dealt with bending- shear behavior in the reinforced concrete beams with Glass- Fibre Reinforced Plastic (GFRP) and Carbon Fibre Reinforced Plastic (CFRP) composites. For this purpose, the concrete reinforced beams have been analyzed by various techniques and using built-in glass and carbon fibers. The carbon- fiber built samples without the end brace and other samples with end- brace were anchored by glass fibers. Similarly, glass-fiber reinforced plastic (GFRP) beams were built with and without bracing at end and reserved under laboratory conditions. These fibers have been installed in tensile point of beams and by means of epoxy adhesive and also one sample was built as control beam without using fibre. On the other hand, some solid and hollow beams were prepared as well.

The reinforced models in this study show that this resisting technique could increase bending strength in beams. The loading of beams has been improved with joints of FRP sheets to the end bracing compared to the beams without end bracing. The phenomenon of flakiness of layers is one of the problems in application of this system where there are several techniques for prevention from this phenomenon including end bracing of fibers by means of fibers and electronic bracing of fibers.

Increase in diameter of layers adds to loading potential in beams. Of course this increase in diameter is relatively followed by increase in loading and there is an optimal limit to increase diameter of layers. Application of glass fibers increases loading potential along with increase in rise of beams and in some cases rise of reinforced beams exceeds from this rate in control beam.

Using plan of concrete mixture with resistance rate $20 \mathrm{MPa}$ in this laboratory test, 14 hollow and solid cylindrical columns were tested. According to the given results, bracing of column by FRP polymer fibers increases compressional strength and rising ductility of column. In analysis of solid and hollow concretes application of FRP in binding of columns increased their resistance and ductility in all of samples. With respect to these findings and in a general comparison one can assume the effect of fiber binding on hollow samples lesser than on solid ones although the effect of binding on hollow 
samples has been also very remarkable and effect of CFRP is greater than GFRP as well.

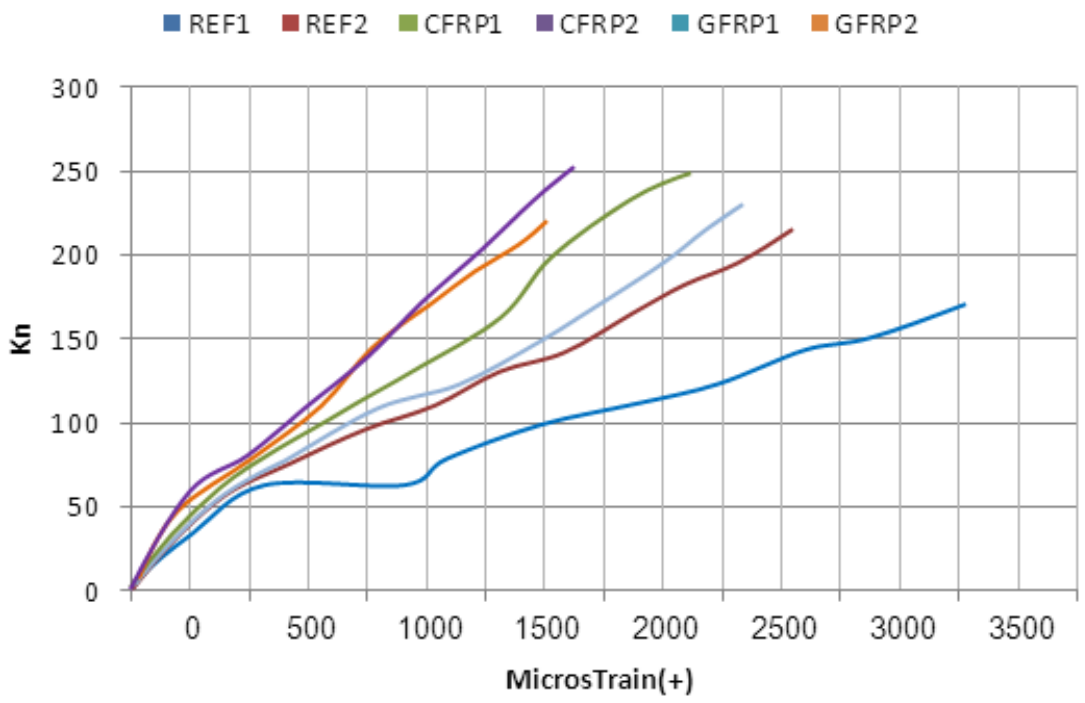

Fig. 13: The related diagram of tensile load- strain of beams

The stress focus has reached to maximum level at the end of fibers and it has caused removal of fibers along with concrete in point of tensile reinforcements. In order to prevent from this phenomenon, the end point of fibers should be adequately far from area of tensile reinforcements. This task was done by attaching the braced fibers in U-shape to the end of joint of fibers.

\section{References}

Abu-Tair AI, Lavery D, Nadjai A, Rigden SR and Ahmed TMA (2000). A new method for evaluating the surface roughness of concrete cut for repair or strengthening. Construction and building materials, 14(3): 171-176.

Arduini M and Nanni A (1997). Parametric study of beams with externally bonded FRP reinforcement. ACI Structural Journal, 94(5): 493501.

Barros JA and Sena-Cruz J (2002). Bond behavior of carbon laminate strips into concrete by pulloutbending tests. In Bond in Concrete: from Research to Standards: Proceedings of the Third International Symposium on Bond in Concrete: 614-621.

Benyoucef S, Tounsi A, Bedia EA and Meftah SA (2007). Creep and shrinkage effect on adhesive stresses in RC beams strengthened with composite laminates. Composites Science and Technology, 67(6): 933-942.

Buyukozturk O, Gunes O and Karaca E (2004). Progress on understanding debonding problems in reinforced concrete and steel members strengthened using FRP composites. Construction and Building Materials, 18(1): 9-19.

Chajes MJ, Finch WW, Januszka TF and Thomson TA (1996). Bond and force transfer of composite material plates bonded to concrete. ACI Structural Journal, 93(2): 208-217.

Chen D and El-Hacha R (2013). Damage tolerance and residual strength of hybrid FRP-UHPC beam. Engineering Structures, 49: 275-283.

Correia JR, Branco FA and Ferreira J (2009). GFRPconcrete hybrid cross-sections for floors of buildings. Engineering Structures, 31(6): 13311343.

Dai J, Ueda T and Sato Y (2005). Development of the nonlinear bond stress-slip model of fiber reinforced plastics sheet-concrete interfaces with a simple method. Journal of Composites for Construction, 9(1): 52-62.

Dai JG, Sato Y, Ueda T (2002). Improving the load transfer and effective bond length for FRP composites bonded to concrete. Proceedings of Japan Concrete Institute, 24(2): 1423-1428.

Dalalbashi A, Eslami A and Ronagh HR (2012). Plastic hinge relocation in RC joints as an alternative method of retrofitting using FRP. Composite Structures, 94(8): 2433-2439.

Gao B, Kim JK and Leung CK (2004). Experimental study on RC beams with FRP strips bonded with rubber modified resins. Composites science and technology, 64(16): 2557-2564.

Gonilha JA, Correia JR and Branco FA (2014). Structural behaviour of a GFRP-concrete hybrid footbridge prototype: experimental tests and numerical and analytical simulations. Engineering Structures, 60: 11-22.

Horiguchi $\mathrm{T}$ and Saeki N (1997). Effect of test methods and quality of concrete on bond strength of CFRP sheet. Non-Metallic (FRP) Reinforcement for Concrete Structures, 1: 265-270.

Julio EN, Branco FA and Silva VD (2004). Concreteto-concrete bond strength. Influence of the 
roughness of the substrate surface. Construction and Building Materials, 18(9): 675-681.

Kang THK, Howell J, Kim S and Lee DJ (2012). A state-of-the-art review on debonding failures of FRP laminates externally adhered to concrete. International Journal of Concrete Structures and Materials, 6(2): 123-134.

Li G and Ghebreyesus A (2006). Fast repair of damaged RC beams using UV curing FRP composites. Composite Structures, 72(1): 105110.

Matana M, Galecki G, Maerz N and Nanni A (2005). Concrete substrate preparation and characterization prior to adhesion of externally bonded reinforcement. In International Symposium on Bond Behaviour of FRP in Structures, International Institute for FRC in Construction, Hong Kong: 133-139.

Mendes PJ, Barros JA, Sena-Cruz JM and Taheri M (2011). Development of a pedestrian bridge with GFRP profiles and fiber reinforced selfcompacting concrete deck. Composite Structures, 93(11): 2969-2982.

Mitsui M, Fukuzawa K, Numao T and Fuda I (2000). Relations between surface roughness indexes and bond strength between CFRP sheets and concrete. Journal-Society of Materials Science Japan, 49(6): 685-691.

Mutsuyoshi H, Shiroki K, Hai ND and Ishihama T (2011). Composite behavior of a pultruded hybrid CFRP-GFRP beam with UFC deck. In Advances in FRP Composites in Civil Engineering, Springer Berlin Heidelberg: 111-114.

Myers J, Jeffries J and Shan X (2007). Effect of varied surface roughness and concrete strength on the bond performance of FRP fabrics. Advanced Composites for Construction. In Advanced Composites in Construction (ACIC 07), University of Bath, Bath, UK.

Naderi M (2007). New twist-off method for the evaluation of in-situ strength of concrete. Journal of Testing and Evaluation, 35(6): 1-7.

Naderi M (2008). Effects of cyclic loading, freezethaw and temperature changes on shear bond strengths of different concrete repair systems. The Journal of Adhesion, 84(9): 743-763.
Naderi M (2009). Analysis of the slant shear test. Journal of Adhesion Science and Technology, 23(2): 229-245.

Naderi M (2011). Using twist-off method for measuring surface strength of concretes cured under different environments. Journal of Materials in Civil Engineering, 23(4): 385-392.

Nakaba K, Kanakubo T, Furuta T and Yoshizawa H (2001). Bond behavior between fiber-reinforced polymer laminates and concrete. Structural Journal, 98(3): 359-367.

Neagoe CA and Gil L (2014). Evaluation of deflections for PFRP-RC hybrid beams with complete and partial shear connection. In the Second International Conference for Phd Students in Civil Engineering and Architecture: Building the community of young researchers: CE-PhD 2014: Cluj-Napoca-ROMANIA: 57-64.

Santos PM and Julio EN (2007). Correlation between concrete-to-concrete bond strength and the roughness of the substrate surface. Construction and Building Materials, 21(8): 1688-1695.

Seo SY, Feo L and Hui D (2013). Bond strength of near surface-mounted FRP plate for retrofit of concrete structures. Composite Structures, 95: 719-727.

Talbot C, Pigeon M, Beaupré D and Morgan DR (1995). Influence of surface preparation on longterm bonding of shotcrete. Materials Journal, 91(6): 560-566.

Toutanji H and Ortiz G (2001). The effect of surface preparation on the bond interface between FRP sheets and concrete members. Composite structures, 53(4): 457-462.

Wambold JC, Henry JJ and Hegmon RR (1982). Evaluation of pavement surface texture significance and measurement techniques. Wear, 83(2): 351-368.

Yoshizawa H, Wu Z, Yuan H and Kanakubo T (2000). Study on FRP-concrete interface bond performance. Journal of Materials, Concrete Structures and Pavements of JSCE, 662(49): 105119.

Yuan H, Lu X, Hui D and Feo L (2012). Studies on FRP-concrete interface with hardening and softening bond-slip law. Composite Structures, 94(12): 3781-3792. 